\title{
Assessment of Anti-corrosion Potentials of Imidazole Derivatives on some Industrial Metals in Various Environments: A Review
}

\author{
Elhachmia Ech-Chihbi ${ }^{1,2}$, Rajae Salim ${ }^{1,2}$, Hassan Oudda ${ }^{1}$, Fadoua El Hajjaji ${ }^{2}$, \\ Shehdeh Jodeh ${ }^{3, *}$ and Mustapha Taleb ${ }^{3}$ \\ ${ }^{1}$ Laboratory of Separation Processes, Faculty of Science, University Ibn Tofail. Kenitra. Morocco \\ ${ }^{2}$ Laboratory of Engineering, Electrochemistry, Modeling and Environment (LIEME), Faculty of \\ Sciences, University Sidi Mohamed Ben Abdellah. Fez. Morocco \\ ${ }^{3}$ Department of Chemistry, An-Najah National University, P. O. Box 7. Nablus. State of Palestine.
}

*Corresponding author: sjodeh@hotmail.com

Received 28/10/2018; accepted 10/02/2021

https://doi.org/10.4152/pea.2021390405

\begin{abstract}
Recently, there were reported investigations in the field of corrosion prevention, about finding effective environment-friendly alternative inhibitors, to replace toxic and harmful compounds. In the present review, the corrosion inhibition of some materials in various corrosive media, using imidazole derivatives, is summarized. Several organic compounds reported by many researchers are herein presented. This review considers previous studies conducted on various inhibitors, and provides an overview of some experimental techniques performed in order to investigate their corrosion properties.
\end{abstract}

Keywords: Imidazole, corrosion inhibitors, environment, techniques.

\section{Introduction}

Metal surfaces are used in an extensive range of industrial applications, including petroleum, textile and food processing industries, as a component of pumps or valves that carry various types of substances [1-3]. Acid solutions are extensively used in diverse industrial fields, such as cleaning, pickling, descaling and oil-well acidizing, especially, sulphuric, hydrochloric, nitric and phosphoric acids [4]. The corrosion of metallic materials causes huge financial losses to industry, which, then, justifies the search for substances that can slow down or prevent metals corrosion rate. Nowadays, it is important to control metal corrosion, in order to expand the life of metallic equipment [5]. Corrosion is an electrochemical or chemical degradation of metals/alloys properties, due to interfacial interactions with their environment [6-7]. This process involves the displacement of metal ions into the electrolyte, at the anode. The cathodic reaction requires oxygen or hydrogen ions as "electron acceptors" [8]. The use of inhibitors is considered one of the best methods of protecting materials against the corrosion process, and it is becoming increasingly common [9-14]. The use of organic 
compounds as inhibitors has gained the highest priority, because they are relatively economic, effective and can be derived from commercially available starting chemicals [15]. Generally, these compounds interact through their $\pi$ - and non-bonding electrons with metal, forming a surface protective film, via coordination bonds. The passive film that is formed acts as a barrier between the environment and the metal surface, thereby helping in corrosion protection [16]. The inhibiting capacity of a large number of organic compounds has been studied. Most organic compounds contain oxygen (O), sulphur (S), nitrogen $(\mathrm{N})$, phosphorus $(\mathrm{P})$, and multiple bonds showed significant inhibition efficiency. Recently, imidazole derivatives were reported, in different studies, as a new class of metals corrosion inhibitors, due to the availability of their $\pi$-electrons of $-\mathrm{C}=\mathrm{N}$ azomethine double bond, which can coordinate with metals, to form a barrier between them and corrosive elements. The aim of this paper is to review and discuss some research works reported on corrosion inhibition, using imidazole derivatives. In addition, the main techniques for corrosion prevention reported in the literature are herein summarized.

\section{Imidazole brief overview}

Imidazole (a) ring is a heterocyclic aromatic compound that contains three carbon and two nitrogen atoms, at $1^{\text {st }}$ and $3^{\text {rd }}$ positions. The systematic name for this compound is "1,3-diazole" [17]. Benzimidazole (b) has a benzene ring fused in the $4^{\text {th }}$ and $5^{\text {th }}$ position.. The molecular structure of $(a)$ and $(b)$ is presented in Fig. 1.

(a)<smiles>c1c[nH]cn1</smiles>

(b)<smiles>c1ccc2[nH]cnc2c1</smiles>

Figure 1. Molecular structures of (a) imidazole and (b) benzimidazole.

The imidazole ring system is, of course, not just interesting and a source of endless research pleasure, but it is also a key system, in its compounds (such as the amino acid "histidine", vitamin B12, a component of DNA base structure, purines, histamine, biotin, etc.); thus, it is an important constituent of many natural products, in pharmaceutical, veterinary and agrochemical products [18]. It also has alkaloids that possess several biological activities, such as antibacterial, anticancer, antitubercular, antifungal, anti HIV, anti-protozoa, anti-inflammatory, anti-mycobacterial, anxiolytic and anti-diabetic activities [19-20].

\section{Imidazole derivatives as corrosion inhibitors in aqueous media}

Recently, imidazole has attracted a lot of attention in the field of metallic corrosion inhibition, due to its interesting properties, low cost and ease of synthesis [21]. It is also environmental friendly, exhibiting significant inhibition efficiency. Imidazole derivatives have been evaluated, by several investigators, as effective corrosion inhibitors, in various media. For example, Yanardag et al. reported the corrosion inhibition efficiencies of some benzimidazole derivatives, for zinc, brass and copper, in alkaline and neutral media [22]. Xinkuai He et al. 
[23], Ingrid Milosev et al. [24] and M. Mahdavian et al. [25] have also reported that imidazole derivatives are effective organic corrosion inhibitors on aluminium, copper and steel. This paper investigates the inhibition potentials of several imidazole derivatives exposed to different media. Table 1 displays the chemical structures of eight imidazole derivatives used in this review, in order to study the inhibitive property of these compounds on various metals (mild/stainless/J55/ P110 steel and aluminum) in different media $\left(\mathrm{HCl}, \mathrm{NaCl}+\mathrm{CO}_{2}, \mathrm{H}_{2} \mathrm{SO}_{4}\right.$ and $\left.\mathrm{H}_{3} \mathrm{PO}_{4}\right)$.

Table 1. List of some imidazole derivatives used as corrosion inhibitors, in different media.

\begin{tabular}{|c|c|c|c|c|}
\hline $\begin{array}{l}\text { Structure of } \\
\text { inhibitor }\end{array}$ & IUPAC name & Techniques & Metal & Electrolyte \\
\hline & $\begin{array}{l}\mathrm{R}=\mathrm{OCH}_{3}: \text { "2-(4- } \\
\text { methoxyphenyl)- } \\
\text { 4,5-diphenyl- } \\
\text { imidazole" } \\
\mathrm{R}=\mathrm{CH}_{3}: \text { "5-diphenyl- } \\
\text { 2-(p-tolyl)-imidazole" } \\
\mathrm{R}=\mathrm{NO}_{2} \text { :"2-(4- } \\
\text { nitrophenyl)-4,5- } \\
\text { diphenyl-imidazole" } \\
{[26]}\end{array}$ & $\begin{array}{l}\text { Weight loss } \\
\text { method, } \\
\text { electrochemical } \\
\text { impedance spectroscopy } \\
\text { (EIS), potentiodynamic } \\
\text { polarization, } \\
\text { SEM, atomic force } \\
\text { microscopy (AFM), X- } \\
\text { ray photoelectron } \\
\text { spectroscopy (XPS) and } \\
\text { quantum chemical } \\
\text { calculation }\end{array}$ & J55 steel & $\begin{array}{l}3.5 \% \mathrm{NaCl}+ \\
\mathrm{CO}_{2}\end{array}$ \\
\hline & $\begin{array}{l}\mathrm{R}=\mathrm{H} \text { : "Imidazole" } \\
\mathrm{R}=\mathrm{CH}_{3}: \text { "Methyl } \\
\text { imidazole" [27] }\end{array}$ & $\begin{array}{l}\text { Potentiodynamic } \\
\text { polarization, EIS, } \\
\text { electrochemical } \\
\text { frequency modulation } \\
\text { (EFM), SEM and } \\
\text { quantum chemical } \\
\text { calculation }\end{array}$ & Aluminum & $0.5 \mathrm{M} \mathrm{HCl}$ \\
\hline $\mathrm{H}$ & $\begin{array}{l}\mathrm{R}=\mathrm{H}: \text { :"Benzimidazole" } \\
\mathrm{R}=\mathrm{CH} 3: \\
\text { "2 } \\
\text { Methylbenzimidazole" } \\
\mathrm{R}=\mathrm{SH}: \\
\text { "2 } \\
\text { Mercaptobenzimidazol } \\
\text { e" [28] }\end{array}$ & $\begin{array}{l}\text { Tafel polarization and } \\
\text { EIS }\end{array}$ & Mild steel & $1 \mathrm{M} \mathrm{HCl}$ \\
\hline\langle\rangle & $\begin{array}{l}\mathrm{R}=\mathrm{H} \text { : "4-(phenyl)-5- } \\
\text { [(2-methyl- 1H- } \\
\text { benzimidazol-1- } \\
\text { yl)methyl]-4H-1,2,4- } \\
\text { triazole-3-thiols" } \\
\mathrm{R}=\mathrm{CH} \text { : "4-(4- } \\
\text { methylphenyl)-5-[(2- } \\
\text { methyl-1H- } \\
\text { benzimidazol-1- } \\
\text { yl)methyl]-4H-1,2,4- } \\
\text { triazole-3-thiols" } \\
\mathrm{R}=\mathrm{OCH} 3: \text { "4-(4 } \\
\text { methoxyphenyl)-5-[(2 } \\
\text { methyl-1H- } \\
\text { benzimidazol-1- }\end{array}$ & $\begin{array}{l}\text { Weight loss- } \\
\text { electrochemical } \\
\text { polarization, EIS, SEM } \\
\text { and Semiemperical } \\
\text { (AM1) }\end{array}$ & Mild steel & $15 \% \mathrm{HCl}$ \\
\hline
\end{tabular}




\begin{tabular}{|c|c|c|c|c|}
\hline & $\begin{array}{l}\text { yl)methyl]-4H-1,2,4- } \\
\text { triazole-3-thiols" }[29]\end{array}$ & & & \\
\hline & $\begin{array}{l}\text { "2-methyl-4-phenyl-1- } \\
\text { tosyl-4, 5- dihydro-1H- } \\
\text { imidazole" [30] }\end{array}$ & $\begin{array}{l}\text { Weight loss, } \\
\text { potentiodynamic } \\
\text { polarization, EIS and } \\
\text { SEM }\end{array}$ & $\begin{array}{l}\text { P110 carbon } \\
\text { steel }\end{array}$ & $1 \mathrm{M} \mathrm{HCl}$ \\
\hline & $\begin{array}{l}\text { "N-vinylimidazole } \\
\text { monomer" }\end{array}$ & \multirow{3}{*}{$\begin{array}{l}\text { Potentiodynamic } \\
\text { polarization and EIS }\end{array}$} & \multirow{3}{*}{ Stainless steel } & \multirow{3}{*}{$1 \mathrm{M} \mathrm{H}_{2} \mathrm{SO}_{4}$} \\
\hline & & & & \\
\hline & $\begin{array}{l}\text { "poly-N- } \\
\text { vinylimidazole" [31] }\end{array}$ & & & \\
\hline$\rangle_{N}^{-N}-R$ & $\begin{array}{l}\mathrm{R}=\mathrm{H}: \\
\text { "Benzimidazole" } \\
\mathrm{R}=\mathrm{CH}_{3}: \text { :2- } \\
\text { methylbenzimidazole" } \\
\mathrm{R}=\mathrm{NH}_{2}: \text { :"2- } \\
\text { aminobemzimidazole" } \\
{[32]}\end{array}$ & $\begin{array}{l}\text { Potentiodynamic } \\
\text { polarization and EIS }\end{array}$ & Mild steel & $1 \mathrm{M} \mathrm{H}_{3} \mathrm{PO}_{4}$ \\
\hline
\end{tabular}

\section{Technical details and definitions}

\section{Weight loss}

Weight loss is the most commonly and the most accurate method used to determine corrosion rate in several studies [33-35]. Often, this technique does not require expensive equipment. The specimens are immersed in corrosive media, for a specific period. Weights changes of the specimens, before and after immersion in corrosive environments, were measured by using an electronic balance. The inhibition efficiency $\left(\eta_{\mathrm{wL}}\right)$ can be estimated by using the following equation [36]:

$$
\eta_{W L}=\frac{W-W_{i n h}}{\mathrm{~W}} * 100
$$

where $\mathrm{W}$ and $\mathrm{W}_{\text {inh }}$ are the values of the corrosion rate, in the inhibitor absence and presence, respectively.

\section{Potentiodynamic polarization measurements}

Potentiodynamic polarization is used to determine the data of corrosion potential ( $\left.\mathrm{E}_{\text {corr }}\right)$ and current density ( $\mathrm{i}_{\text {corr }}$ [37]. The system consists of a three electrode unit directly connected to a potentiostat. The three electrodes are the working electrode (WE), reference electrode (RE), and counter (or auxiliary) electrode 
(CE). The reference electrode most commonly used is the saturated calomel electrode (SCE) [27-30, 38, 39] and $\mathrm{Ag} / \mathrm{AgCl}[25,31]$. For an electrochemical reaction under pure activation control, polarization curves exhibit a linear behavior in the applied potential vs. current or log (i) plots, called Tafel behavior (i.e., linear on semi-logarithmic scale) [37]. Corrosion rate or corrosion current density $\left(\mathrm{i}_{\text {corr }}\right)$ is obtained by extrapolating both cathodic and anodic Tafel regions back to the corrosion potential ( $\left.E_{\text {corr }}\right)$. The corrosion inhibition efficiency $\left(\eta_{p p}\right)$ is determined by following equation [40-42]:

$$
\eta_{P P}=\frac{i_{\text {corr }}^{0}-i_{\text {corr }}}{i_{\text {corr }}^{0}} * \mathbf{1 0 0}
$$

where $\mathrm{i}_{\text {corr }}^{0}$ and $\mathrm{i}_{\text {corr }}$ are the corrosion current densities values, in the inhibitor absence and presence, respectively.

\section{Electrochemical impedance spectroscopy (EIS)}

Electrochemical impedance spectroscopy (EIS) is a powerful and effective technique which can be used to study the electrical properties of the electrode/ electrolyte interface. EIS is used to characterize electrochemical systems and measure impedance changes in these systems [43]. The principle of this technique is to apply a small amplitude $(1-10 \mathrm{mV})$ ac sinusoidal signal of potential or current, in a wide range of frequencies, to an electrode inserted into an electrolyte, in order to measure the current response [43]. The EIS measurements are interpreted through graphical representations. The Nyquist plot represents the impedance imaginary part vs the impedance real part $\left(Z=Z_{\text {real }}+j Z_{i m}\right)$. The second representation is called Bode diagram, which represents the logarithm of the impedance modulus $(\log |Z|)$ and the phase shift vs. the frequency logarithm $(\log f)$ [44]. The inhibition efficiency $\left(\eta_{\text {imp }}\right)$ was determined using the following equation [45-46]:

$$
\eta_{i m p}=\frac{R_{c t}-R_{c t}^{0}}{R_{c t}} * 100
$$

where $\mathrm{R}_{\mathrm{ct}}^{0}$ and $\mathrm{R}_{\mathrm{ct}}$ are the charge transfer resistance values, in the inhibitor absence and presence, respectively. The interpretation of the impedance spectra requires the selection of an "equivalent circuit" that suitably fits the experimental data [4749]. Nyquist plots, which possess incomplete capacitive semicircles, characterize a non-ideal capacitance behavior, leading to the inclusion of a constant phase element (CPE) in the proposed equivalent circuit. G. Karthik and M. Sundara Vadivelu [50] have introduced this element into the equivalent circuit, to fit the impedance data.

\section{X-ray photoelectron spectroscopy}

$\mathrm{X}$-ray photoelectron spectroscopy (XPS) is a quantitative technique that is capable of identifying elemental compositions and analyzing the outermost molecular layers of a material [51]. XPS is a surface characterization technique based on the photoelectron effect, i.e., emission of an electron following the excitation of core level electrons by photons. This technique surveys the electron binding energy 
spectrum of a sample surface, resulting in a plot of binding energy versus total electron count [52].

\section{Scanning electron microscopic (SEM)}

SEM is the best known and mostly applied of the surface analytical methods [53]. SEM is able to obtain information, such as the texture (morphological aspects) and orientation of components, as well as the crystalline structure of the sample. Different models are used to characterized the surface morphology in some works that have been reported in this article, such as: JOEL, JSM-T20, Japan [27]; JEOL JSM - 6380, LA [29]; and SEM JSM-7500F, Japan [30].

\section{Atomic force microscopy (AFM)}

The AFM technique is a powerful tool used to quantify the surface morphology of a metal/solution interface [54]. This technique was developed from scanning tunnel microscopy with nanometer resolution [55]. Atomic force microscopy is a high precision technique that provides the material topography and chemical composition of a metal surface, with high spatial resolution [54]. Some authors in the field of corrosion have employed AFM , for example, Yujie Qiang et al. (2017) and Paulina Arellanes-Lozada et al. (2018) [56, 57].

\section{Quantum chemical calculations}

Theoretical chemistry, such as quantum chemical calculations, has been recently used to analyze the adsorption mechanism of inhibitors on a metal surface. The use of quantum chemical calculations is very important, in order to establish correlations between the inhibitive effect and the structure of the molecule [58]. Recently, computational modeling techniques have been successfully applied to corrosion phenomena, as summarized in some articles by J. Haque et al. [59] and N. Anusuya [60]. A. Singh et al. have studied the corrosion inhibiting effect using density functional theory (DFT) method, with hybrid function of Becke three parameters; the same was made by Lee, Yang and Parr (B3LYP), with 6-31G (d) basis set. L. H. Madkour et al. and I. H. Elshamy [61] have also used DFT/B3LYP with 6-31G $(\mathrm{d}, \mathrm{p})$, for seven benzimidazole derivatives. The molecular geometry has a significant influence on the inhibitor adsorption onto a metal surface, as it informs of the optimal way by which the inhibitor might cover the metal surface [1]. Inhibitor molecules that have high electron planar geometry always produce stronger adsorption onto the metal surface than those molecules that have less planar geometry [62]. Quantum chemical parameters, such as EHOMO, ELUMO, energy gap $\left(\Delta E_{g a p}\right)$, dipole moment $(\mu)$, total energy $(\mathrm{TE})$, absolute hardness $(\eta)$ and absolute electronegativity can be estimated, in order to study the chemical reactivity of molecules and their inhibition potentials.

\section{Adsorption of corrosion inhibitor and its isotherms}

Organic corrosion inhibitors reduce the corrosive attack through the adsorption onto the material surface, followed by the formation of a protective layer [63]. According to Moretti [64], organic inhibitors can be adsorbed onto the interface 
metal/solution, by replacing one or more adsorbed water molecules $\left(\mathrm{H}_{2} \mathrm{O}_{\text {ads }}\right)$ in the aqueous solution, as shown by the following equation:

$$
\operatorname{Org}_{(\text {(sol) }}+\mathbf{n ~ H}_{2} \mathrm{O}_{(\text {ads })} \leftrightarrow \operatorname{Org}_{(\text {ads })}+\mathbf{n ~ H}_{2} \mathbf{O}_{(\text {sol) }}
$$

where $\mathrm{n}$ is the number of bipolar molecules of water replaced by one inhibitor molecule. The adsorption process depends on the metal surface charge, type of electrolyte, molecular structure and electrical characteristics of an organic inhibitor [65]. The adsorption process of corrosion inhibitors onto the metallic surface can be described by two main types of interaction: physisorption and chemisorption. The first type is the result of electrostatic and Van Der Waals interactions between the organic ions and the electrically charged metal surface [66]. De Philip A. has also reported that chemisorption involves charge transfer from the inhibitor molecules to the atoms of the metal surface, in order to form a coordinate type of bond [66]. The interactive nature of corrosion inhibitors with metal surfaces can be explained using various adsorption isotherm models.

\section{Langmuir isotherm}

The Langmuir isotherm model explains adsorption by assuming monolayer coverage on a homogeneous surface with identical adsorption sites [67]. Langmuir isotherm, which represents the best fit of experimental data, can be expressed as follows [67]:

$$
\frac{C_{i n h}}{\theta}=C_{i n h}+\frac{1}{K}
$$

where $\theta$ is the degree of surface coverage, $K$ is the constant describing the adsorption/desorption equilibrium and $\mathrm{C}$ is the inhibitor concentration.

\section{Frumkin isotherm}

The adsorption process of corrosion inhibitor described by the Frumkin isotherm is given by the following equation [68]:

$$
K C=\frac{\theta}{1-\theta} e^{-f \theta}
$$

where $\theta$ is the degree of surface coverage, $\mathrm{C}$ is the inhibitor concentration, $\mathrm{f}$ is the constant of attraction and $\mathrm{K}$ is the equilibrium constant of adsorption/desorption. The value of $f$ parameter depends on the interaction between an adsorbed molecule and a metallic surface and also on the degree of surface heterogeneity.

\section{Flory-Huggins}

The Flory-Huggins model is believed to be a substitutional model, i.e., which describes the substitution of inhibitor molecules for water molecules [68]. The Flory-Huggins adsorption isotherm can be linearly expressed as follows [69]:

$$
\frac{\theta}{x(1-\theta)^{x}}=\mathbf{K C}
$$

where $\theta$ is the degree of inhibitor surface coverage, $\mathrm{K}$ is the equilibrium constant of adsorption/desorption and $\mathrm{x}$ is the number of water molecules replaced by the inhibitor molecule. M. Saadawy [70] has used Flory-Huggins model to fit the corrosion data of three anions in the $\mathrm{H}_{2} \mathrm{SO}_{4}$ solution. 


\section{Results and discussions}

Corrosion rate and inhibition efficiency of reported imidazole compounds (Table 1), in different media, have been studied. Percentage inhibition efficiency values, obtained through weight loss, potentiodynamique polarization and electrochemical impedance spectroscopy techniques, are given in Table 2.

Table 2. Extracted results obtained on the corrosion inhibition behavior of different compounds in different media.

\begin{tabular}{|c|c|c|c|c|c|c|c|c|}
\hline Inhibitor & Conc. & $\begin{array}{c}\mathbf{T} \\
(\mathbf{K})\end{array}$ & Medium & $\begin{array}{c}\eta_{W L} \\
\%\end{array}$ & $\begin{array}{c}\eta_{\mathrm{PP}} \\
\%\end{array}$ & $\eta_{\text {imp }} \%$ & $\begin{array}{l}\text { Adsorption } \\
\text { isotherm }\end{array}$ & Ref. \\
\hline $\begin{array}{c}\text { 2-(4-methoxyphenyl)- } \\
\text { 4,5-diphenyl-imidazole (M-1) }\end{array}$ & $400 \mathrm{mg} / \mathrm{L}$ & 308 & $3.5 \% \mathrm{NaCl}+\mathrm{CO}_{2}$ & 93 & 90 & 92.4 & \multirow{3}{*}{ Langmuir } & \multirow{3}{*}{26} \\
\hline $\begin{array}{l}\text { 4,5-diphenyl-2-(p-tolyl)- } \\
\text { imidazole (M-2) }\end{array}$ & $400 \mathrm{mg} / \mathrm{L}$ & 308 & $3.5 \% \mathrm{NaCl}+\mathrm{CO}_{2}$ & 83 & 84 & 83.4 & & \\
\hline $\begin{array}{c}\text { 2-(4-nitrophenyl)-4,5- } \\
\text { diphenyl-imidazole (M-3) }\end{array}$ & $400 \mathrm{mg} / \mathrm{L}$ & 308 & $3.5 \% \mathrm{NaCl}+\mathrm{CO}_{2}$ & 81 & 77 & 81.2 & & \\
\hline Imidazole (A) & $18.10^{-5} \mathrm{M}$ & 303 & $0.5 \mathrm{M} \mathrm{HCl}$ & - & 70.7 & 66 & \multirow{2}{*}{ Frumkin } & \multirow{2}{*}{ [27] } \\
\hline Methyl imidazol (B) & $18.10^{-5} \mathrm{M}$ & 303 & $0.5 \mathrm{M} \mathrm{HCl}$ & - & 76 & 69.2 & & \\
\hline Benzimidazole (BI) & $250 \mathrm{ppm}$ & 298 & $1 \mathrm{M} \mathrm{HCl}$ & - & 52.2 & 73.8 & \multirow{3}{*}{ Langmuir } & \multirow{3}{*}[28]{} \\
\hline $\begin{array}{l}\text { 2-Methylbenzimidazole (2- } \\
\text { CH3-BI) }\end{array}$ & $250 \mathrm{ppm}$ & 298 & $1 \mathrm{M} \mathrm{HCl}$ & - & 57.1 & 76.3 & & \\
\hline $\begin{array}{l}\text { 2-Mercaptobenzimidazole } \\
\text { (2-SH-BI) }\end{array}$ & $250 \mathrm{ppm}$ & 298 & $1 \mathrm{M} \mathrm{HCl}$ & - & 88.7 & 90.4 & & \\
\hline $\begin{array}{l}\text { 4-(phenyl)-5-[(2-methyl-1H- } \\
\text { benzimidazol-1-yl)methyl]-4H- } \\
\text { 1,2,4-triazole-3-thiols (Inh I) }\end{array}$ & 200 ppm & 303 & $15 \% \mathrm{HCl}$ & - & 82.1 & 81.1 & \multirow{3}{*}{ Langmuir } & \multirow{3}{*}{ [29] } \\
\hline $\begin{array}{c}\text { 4-(4-methylphenyl)-5-[(2- } \\
\text { methyl-1Hbenzimidazol-1- } \\
\text { yl)methyl]-4H-1,2,4-triazole-3- } \\
\text { thiols (Inh II) }\end{array}$ & 200 ppm & 303 & $15 \% \mathrm{HCl}$ & - & 85.1 & 83.9 & & \\
\hline $\begin{array}{c}\text { 4-(4-methoxyphenyl)-5-[(2- } \\
\text { methyl-1H-benzimidazol-1- } \\
\text { yl)methyl]-4H-1,2,4-triazole-3- } \\
\text { thiols (Inh III) }\end{array}$ & 200 ppm & 303 & $15 \% \mathrm{HCl}$ & 96.4 & 90.5 & 87.1 & & \\
\hline $\begin{array}{l}\text { 2-methyl-4-phenyl-1-tosyl-4, 5- } \\
\text { dihydro-1H-imidazole (IMI) }\end{array}$ & $300 \mathrm{mg} / \mathrm{L}$ & 333 & $1 \mathrm{M} \mathrm{HCl}$ & 94.6 & 96.88 & 96.64 & Langmuir & {$[30]$} \\
\hline $\begin{array}{c}\mathrm{N} \text {-vinylimidazole monomer } \\
(\mathrm{NVI})\end{array}$ & $5.10^{-2} \mathrm{M}$ & 296 & $1 \mathrm{M} \mathrm{H}_{2} \mathrm{SO}_{4}$ & - & 94 & - & \multirow{3}{*}{ Langmuir } & \multirow{3}{*}[31]{} \\
\hline \multirow[t]{2}{*}{ poly-N-vinylimidazole (PNVI) } & $\begin{array}{c}14 \mu \mathrm{m} \\
\text { (Coating } \\
\text { thicknes) } \\
\end{array}$ & 296 & $1 \mathrm{M} \mathrm{H}_{2} \mathrm{SO}_{4}$ & - & 85.1 & 99.1 & & \\
\hline & $2.65 \mathrm{mM}$ & 298 & $1 \mathrm{M} \mathrm{H}_{2} \mathrm{SO}_{4}$ & - & 40 & - & & \\
\hline Benzimidazole (BI) & $5.10^{-2} \mathrm{M}$ & 298 & $1 \mathrm{M} \mathrm{H}_{3} \mathrm{PO}_{4}$ & - & 62 & 62.1 & \multirow{3}{*}{ Flory-Huggins } & \multirow{3}{*}[32]{} \\
\hline $\begin{array}{c}\text { 2-methyl benzimidazole } \\
\text { (2MBI) }\end{array}$ & $5.10^{-2} \mathrm{M}$ & 298 & $1 \mathrm{M} \mathrm{H}_{3} \mathrm{PO}_{4}$ & - & 55.60 & 51.3 & & \\
\hline 2-aminobenzimidazole (2ABI) & $\begin{array}{c}5.10^{-2} \\
\mathrm{M}\end{array}$ & 298 & $1 \mathrm{M} \mathrm{H}_{3} \mathrm{PO}_{4}$ & - & 69.28 & 69.5 & & \\
\hline
\end{tabular}

The corrosion behavior of $\mathrm{J} 55$ steel, in $3.5 \% \mathrm{NaCl}$ saturated with a $\mathrm{CO}_{2}$ solution, in the absence and presence of three imidazole derivatives, was investigated by A. Singh et al. [26], using various techniques: weight loss, EIS, and potentiostatic polarization. The authors found that the inhibition action of the tested compounds depends on their concentration and chemical structure. M-1 represents the better inhibitor in the given series, exhibiting the best inhibition efficiency of $93 \%$, at the concentration of $400 \mathrm{mg} / \mathrm{L}$, after $3 \mathrm{~h}$, due to the presence of methoxy $\left(\mathrm{OCH}_{3}\right)$, as 
an electron donating group. The adsorption process followed Langmuir isotherm. In the presence of these compounds, J55 steel surface is shown in SEM and AFM micrographs, exhibiting a smooth and uniform morphology, due to the formation of a passive film on the metal surface. Surface analysis (XPS) was also investigated, to discuss the inhibition mechanism of the studied inhibitors on J55 steel, in a $3.5 \% \mathrm{NaCl}+\mathrm{CO}_{2}$ medium.

M. N. El-Haddad et al. [27] studied the electrochemical behaviour of aluminum in a $0.5 \mathrm{HCl}$ solution with imidazole (A) and methyl imidazole (B). The addition of (A) and (B) compounds led to an increase in the corrosion inhibition efficiency. The maximum corrosion inhibition efficiencies obtained by potentiodynamique polarization were $70.7 \%$ for (A) and $76 \%$ for (B), at a $18.10^{-5} \mathrm{M}$ concentration. The corrosion inhibition process was based on the adsorption of these compounds and on the formation of an adhered layer onto the metal surface. This film was characterized using scanning electron microscopy (SEM). The nature of inhibition was found to be of mixed type, predominantly cathodic. EIS measurements were interpreted and explained according to a suitable circuit model, using fitting software. Some activated thermodynamic parameters were computed, indicating that both physical and chemical adsorption may occur on aluminum surface. Furthermore, some quantum chemical parameters, as well as some other structural parameters, have been calculated to understand the inhibition mechanism of imidazole derivatives.

The effects of Benzimidazole (BI), 2 Methylbenzimidazole (2 CH3-BI) and 2 Mercaptobenzimidazole 2-(SH-BI) on mild steel, in a $1 \mathrm{M} \mathrm{HCl}$ solution, were studied by J. Aljourani et al, using polarization and impedance measurements [28]. The corrosion current densities ( $i_{\text {corr }}$ ) decreased in the following order: BI $>2$ $\mathrm{CH} 3-\mathrm{BI}>2-\mathrm{SH}-\mathrm{BI}$. This result indicates the high beneficial effect of 2-SH-BI $\left(\eta_{\text {imp }}=90.4 \%\right.$ at $\left.250 \mathrm{ppm}\right)$ on mild steel corrosion inhibition, in molar hydrochloric acid. Adsorption isotherm results demonstrated that the adsorption process obeyed Langmuir isotherm. $\mathrm{R}_{\mathrm{tc}}$ has increased with higher concentrations of the tested compounds. $\mathrm{C}_{\mathrm{dl}}$ values have decreased and were brought down to the maximum extent, with higher inhibitors concentration, which was most probably caused by the increase in the thickness of the electrical double layer. This suggests that these inhibitors act via adsorption at the metal/electrolyte interface. The obtained thermodynamic parameters of adsorption indicated that the corrosion inhibitor mechanism has retarded corrosion processes, through physical adsorption.

The inhibiting activity of some substituted imidazoles in $15 \% \mathrm{HCl}$, in relation to inhibitor concentrations, using electrochemical techniques, was studied by $\mathrm{M}$. Yadav and S. Kumar. The inhibition efficiencies followed the order: Inh I $<$ Inh II $\left(-\mathrm{CH}_{3}\right)<$ Inh III $\left(-\mathrm{OCH}_{3}\right)$. The adsorption of these compounds onto the mild steel surface obeyed the Langmuir isotherm model. The polarization curves revealed that all the studied inhibitors acted as mixed type inhibitors. The calculated values of the free energy of adsorption suggested that the adsorption of the three molecules involved chemisorption. The inhibitors created a smooth surface, indicating that the corrosion rate was significantly reduced. The geometry optimizations of the three molecules were obtained by application of the 
unrestricted Hartre Fock (UHF) method, using AM1. The highest value of EHOMO $(-8.6541 \mathrm{eV})$ and the lowest value of $\Delta \mathrm{E}(7.9472 \mathrm{eV})$ reflects a higher adsorption capability of Inh III onto the mild steel surface than that of Inh I and Inh II.

The inhibiting effect of 2-methyl-4-phenyl-1-tosyl-4 and 5- dihydro-1H-imidazole on the dissolution of $\mathrm{P} 110$ carbon steel, in a $1 \mathrm{M} \mathrm{HCl}$ solution, was studied by Lei Zhang [30], using weight loss measurements, EIS and potentiodynamic polarization techniques. The author, using EIS technique, concluded that the inhibition effectiveness increased with higher additive concentrations, reaching $96.64 \%$ at $300 \mathrm{mg} / \mathrm{L}$. The adsorption isotherm confirms the applicability of Langmuir's equation to explain the adsorption process of the tested molecule. The displacements of corrosion potential were lower than $85 \mathrm{mV}$, compared to those of the uninhibited solution, indicating that IMI acted as a mixed-type inhibitor. The SEM analysis indicates that IMI can remarkably protect carbon steel from aggressive media, due to the formation of a protective layer on the metal surface.

The inhibitive action of the extract of two imidazole derivatives, namely $\mathrm{N}$ vinylimidazole monomer and poly-N-vinylimidazole, on stainless steel, in a $1 \mathrm{M}$ $\mathrm{H}_{2} \mathrm{SO}_{4}$ acid medium, was investigated by Öncül et al. [31], using weight loss, potentiostatic and potentiodynamic polarization techniques. Experimental results clearly demonstrate the ability of either PNVI or its monomer to reduce the corrosion process that occurs on stainless steel. The inhibition efficiency increases with a higher monomer concentration. The best inhibition, 94\%, was obtained by adding $5.10^{-2} \mathrm{M}$ of monomer into the corrosive environment. The inhibition mechanism of N-vinylimidazole was discussed in view of Langmuir isotherm model. The inhibitory character of the polymer depends upon the thickness and porosity of the film. The increase in thickness and the decrease in porosity improved the coating corrosion resistance.

The inhibition performance of three imidazole compounds on mild steel corrosion, in a $1 \mathrm{M} \mathrm{H}_{3} \mathrm{PO}_{4}$ solution, was studied by A. Ghanbari [32], using electrochemical measurements. The inhibition performance depended on the chemical structure and followed the sequence $2 \mathrm{ABI}>\mathrm{BI}>2 \mathrm{MBI}$. The best fit of the impedance data was obtained using a constant-phase element (CPE), rather than an ideal capacitor. The charge transfer resistance of Benzimidazole (BI), 2 aminobenzimidazole (2ABI) and 2-methyl Benzimidazole (2MBI) increased slightly, indicating the formation of an insulating protective film at the metal/corrosive medium interface. The obtained results show that these compounds were adsorbed onto the mild steel surface, following Flory-Huggins isotherm model, and that each inhibitor molecule replaced 3-5 molecules of water molecules on the steel surface. The inhibited solution $\mathrm{pH}$ moved towards more alkali levels, and the solution resistance (Rs) increased with higher concentrations of the tested compounds, which indicates protonation of inhibitor molecules. $\Delta G_{\text {ads }}^{0}$ shows that the inhibitors adsorbed onto the steel surface, through physical and chemical adsorption.

\section{Conclusion}

The finding of new and efficient imidazole derivatives has been the goal of many research projects. Corrosion inhibition depends on the molecular structure of the inhibitors and on their affinities for the metal surface. The most efficient corrosion 
inhibitors are those compounds containing hetero atoms, such as nitrogen $(\mathrm{N})$ and oxygen (O), as well as aromatic rings. According to the chemical and electrochemical techniques, it is obvious that the metal corrosion rate decreased with higher inhibitor concentrations. Imidazole derivatives exhibited relatively high inhibition efficiencies for various industrial metals, in different mediums. All the inhibitors interacted with the metal surface, forming a passive film or an adsorbed layer that acted as barrier films.

\section{References}

1. Kabanda MM, Obot IB, Ebenso EE. Computational Study of Some Amino Acid Derivatives as Potential Corrosion Inhibitors for Different Metal Surfaces and in Different Media. Int J Electrochem Sci. 2013;8;10839.

2. Vazirinasab E, Jafari R, Momen G. Application of superhydrophobic coatings as a corrosion barrier: A review. Surf Coat Technol. 2013;341:40

3. Goyal M, Kumar S, Bahadur I, et al. Organic corrosion inhibitors for industrial cleaning of ferrous and nonferrous metals in acidic solutions: A review. J Mol Liq. 2018;256:565.

4. Krishnegowda PM, Venkatesha VT, Krishnegowda PKM, et al. Acalypha Torta leaf extract as green corrosion inhibitor for mild steel in hydrochloric acid solution. Ind Eng Chem Res. 2013;52:722.

5. Wazzan NA, Obot IB, Kaya S. Theoretical modeling and molecular level insights into the corrosion inhibition activity of 2-amino-1,3,4-thiadiazole and its 5-alkyl derivatives. J Mol Liq. 2016;221:579.

6. El Adnani Z, Benjelloun AT, Benzakour M, et al. DFT-based QSAR Study of Substituted Pyridine-Pyrazole Derivatives as Corrosion Inhibitors in Molar Hydrochloric Acid. Int J Electrochem Sci. 2014;9:4732.

7. Amjad Z, Demadis K (eds). Mineral Scales and Deposits. 1st Edition. New York: Elsevier:2015.

8. Abdullah Dar M. A review: plant extracts and oils as corrosion inhibitors in aggressive media. Ind Lubr Tribol. 2011;63:227.

9. Abd El-Raouf M, Khamis EA, Abou Kana MTH, et al. Electrochemical and quantum chemical evaluation of new bis (coumarins) derivatives as corrosion inhibitors for carbon steel corrosion in $0.5 \mathrm{M} \mathrm{H} \mathrm{H}_{2} \mathrm{SO}_{4}$. $\mathrm{J}$ Mol Liq. 2018;255:341.

10. Mohan R, Joseph A. Corrosion protection of mild steel in hydrochloric acid up to $313 \mathrm{~K}$ using propyl benzimidazole: Electroanalytical, adsorption and quantum chemical studies. Egypt J petrol. 2018;2711.

11. Abd El Rehim SS, Sayyah SM, El-Deeb MM, et al. Adsorption and corrosion inhibitive properties of $\mathrm{P}(2$-aminobenzothiazole) on mild steel in hydrochloric acid media. Int J Ind Chem. 2016;7:39.

12. Solmaz R. Investigation of the inhibition effect of 5-((E)-4-phenylbuta-1,3dienylideneamino)- 1,3,4-thiadiazole-2-thiol Schiff base on mild steel corrosion in hydrochloric acid. Corros Sci. 2010;52:3321. 
13. Ouakki M, Rbaa M, Galai M, et al. Experimental and Quantum Chemical Investigation of Imidazole Derivatives as Corrosion Inhibitors on Mild Steel in 1.0 M Hydrochloric Acid. J Bio Tribo-Corros. 2018;4:35.

14. Chris OA, Emeka EO. Evaluation of anticorrosion properties of Chrysophyllum albidum leaves extract for mild steel protection in acidic media. Int J Ind Chem. 2016;7:81.

15. Ansari FA, Verma C, Siddiqui YS, et al. Volatile corrosion inhibitors for ferrous and non-ferrous metals and alloys: A review. Int J Corros Scale Inhib. 2018;7:126.

16. Verma C, Olasunkanmi L, Obot I, et al. 5-Arylpyrimido- [4,5-b]quinolinediones as new and sustainable corrosion inhibitors for mild steel in $1 \mathrm{M} \mathrm{HCl}$ : a combined experimental and theoretical approach. RSC Adv. 2016;6:15639.

17. Chawla A, Sharma A, Sharma AK. Review: A convenient approach for the synthesis of imidazole derivatives using microwaves. Der Pharma Chemica. 2012;4:116.

18. Grimmett MR. Imidazole and Benzimidazole Synthesis, Best Synthetic Methods. New York: Academic Press; 1997.

19. Verma A, Joshi S, Singh D, et al. Imidazole: Having Versatile Biological Activities. J Chem. 2013;1.

20. Narasimhan B, Sharma D, Kumar P. Biological importance of imidazole nucleus in the new millennium. Med Chem Res. 2011;20:1119.

21. Verma C, Olasunkanmia LO, Ebensoa EE, et al. Substituents effect on corrosion inhibition performance of organic compounds in aggressive ionic solutions: A review. J Mol Liq. 2018;251:100.

22. Yanardag T., Özbay S., Dinçer S., et al. Corrosion Inhibition Efficiency of Benzimidazole and Benzimidazole Derivatives for Zinc, Copper and Brass. Asian J Chem. 2012;24:47.

23. He X, Jiang $\mathrm{Y}$, Li $\mathrm{C}$, Wang $\mathrm{W}$, et al. Inhibition properties and adsorption behavior of imidazole and 2-phenyl-2-imidazoline on AA5052 in $1.0 \mathrm{M} \mathrm{HCl}$ solution. Corros Sci. 2014;83:124.

24. Milosev I, Kovacevic N, Kovac J, Kokalj A et al. The roles of mercapto, benzene and methyl groups in the corrosion inhibition of imidazoles on copper: I. Experimental characterization. Corros Sci. 2015;98:107.

25. Mahdavian M, Ashhari S. Corrosion inhibition performance of 2 mercaptobenzimidazole and 2-mercaptobenzoxazole compounds for protection of mild steel in hydrochloric acid solution. Electrochim Acta. 2010;55:1720.

26. Singh A, Ansari KR, Kumar A, et al. Electrochemical, surface and quantum chemical studies of novel imidazole derivatives as corrosion inhibitors for J55 steel in sweet corrosive environment. J Alloy Compd. 2017;712:121.

27. El-Haddad MN, Fouda AS. Electroanalytical, quantum and surface characterization studies on imidazole derivatives as corrosion inhibitors for aluminum in acidic media. J Mol Liq. 2015;209:480.

28. Aljourani J, Raeissi K, Golozar MA. Benzimidazole and its derivatives as corrosion inhibitors for mild steel in $1 \mathrm{M} \mathrm{HCl}$ solution. Corros Sci. 2009; $51: 1836$. 
29. Yadav M, Kumar S, Sinha RR, et al. Experimental and Quantum Chemical Studies on Corrosion Inhibition Performance of Benzimidazole Derivatives for Mild Steel in HCl. Ind Eng Chem Res. 2013;52:6318.

30. Zhang L, He Y, Zhou Y, et al. A novel imidazoline derivative as corrosion inhibitor for P110 carbon steel in hydrochloric acid environment. Petroleum. 2015;1:237.

31. Öncül A, Coban K, Sezer E, et al. Inhibition of the corrosion of stainless steel by poly-N-vinylimidazole and N-vinylimidazole. Prog Org Coat. 2011;71:167.

32. Ghanbari A, Attar MM, Mahdavian M. Corrosion inhibition performance of three imidazole derivatives on mild steel in1 $\mathrm{M}$ phosphoric acid. Mater Chem Phys. 2010;124:1205.

33. Ech-chihbi E, Salim R, Oudda H, et al. Effect of some imidazopyridine compounds on carbon steel corrosion in hydrochloric acid solution. Der Pharma Chemica. 2016;8:214.

34. Salim R, Ech-chihbi E, Oudda $H$, et al. The inhibition effect of imidazopyridine derivatives on C38 steel in hydrochloric acid solution. Der Pharma Chemica. 2016;8:200.

35. Saady A, Ech-chihbi E, Rais Z, et al. Inhibition effects of a new syntheses aniline derivative on the corrosion of carbon steel in hydrochloric acid solution. Der Pharma Chemica. 2016;8:133.

36. Alaoui K, Touir R, Galai M, et al. Electrochemical and Computational Studies of Some Triazepine Carboxylate Compounds as Acid Corrosion Inhibitors for Mild Steel. J Bio Tribo-Corros. 2018;4:37.

37. Pérez OR, Sotelo O, Vázquez M, et al. The Electrochemical Behavior and Heat Removal Study during the Solidification Process of an Al-base Alloy. Int J Electrochem Sci. 2017;12:733.

38. Mihajlović MBP, Radovanović MB, Tasić ŽZ, et al. Imidazole based compounds as copper corrosion inhibitors in seawater. $\mathrm{J}$ Mol Liq. 2017;225:127.

39. Gopi D, Sherif EM, Surendiran M, et al. Experimental and theoretical investigations on the inhibition of mild steel corrosion in the ground water medium using newly synthesized bipodal and tripodal imidazole derivatives. Mater Chem Phys. 2014;14:572.

40. Rbaa M, Galai M, El Kacimi Y, et al. Adsorption Properties and Inhibition of Carbon Steel Corrosion in a Hydrochloric Solution by 2-(4,5-diphenyl-4,5dihydro-1h-imidazol-2-yl)-5-methoxyphenol. Port Electrochim Acta. 2017;35:323.

41. Dkhireche N, Galai M, El Kacimi Y, et al. New Quinoline Derivatives as Sulfuric Acid Inhibitor's for Mild Steel. Anal Bioanal Electrochem. 2018;10:111.

42. Chaitra TK, Mohana KN, Tandon HC. Comparative study of Levofloxacin and its amide derivative as efficient water soluble inhibitors for mild steel corrosion in hydrochloric acid solution. Int J Ind Chem. 2017;8:1.

43. Pyun S, Shin H, Lee J, Go JY. Electrochemistry of Insertion Materials for Hydrogen and Lithium. Heidelberg: Spring;2012. 
44. Landolt D. Corrosion and surface chemistry of metals. New York: EPFL Press; 2007. p 216.

45. El-Hajjaji F, Messali M, Aljuhani A, et al. Pyridazinium-based ionic liquids as novel and green corrosion inhibitors of carbon steel in acid medium: Electrochemical and molecular dynamics simulation studies. J Mol Liq. 2018;249:997.

46. Salim R, Elaatiaoui A, Benchat N, et al. Corrosion behavior of a smart inhibitor in hydrochloric Acid molar: Experimental and theoretical studies. JMES. 2017;8:3747.

47. Mansfeld F. Use of electrochemical impedance spectroscopy for the study of corrosion protection by polymer coatings. J Appl Electrochem. 1995;25:187.

48. Valcarce MB, Vázquez M. Carbon steel passivity examined in solutions with a low degree of carbonation: the effect of chloride and nitrite ions. Mater Chem Phys. 2009;115:313.

49. Zaid B, Maddache N, Saidi D, et al. Electrochemical evaluation of sodium metabisulfite as environmentally friendly inhibitor for corrosion of aluminum alloy 6061 in a chloride solution. J Alloy Compd. 2015;629;188.

50. Karthik G, Sundaravadivelu M. Experimental and theoretical studies of antiulcer drugs with benzimidazole rings as corrosion inhibitor for copper in 1 M nitric acid medium. J Adhes Sci Technol. 2017;3:530.

51. Dimitriou MD, Kramer EJ, Hawker CJ. Advanced Techniques for the Characterization of Surface Structure in Polymer Thin Films and Coatings. Arab J Sci Eng. 2014;39:1.

52. Cooper LS, Guan J Adv Polyurethane Biomaterials. 2016;108:30.

53. Braun D, Cherdron H, Rehahn M, et al. Polymer Synthesis: Theory and Practice Fundamentals, Methods, Experiments. 5th Edition. Berlin: Spring; 2005.

54. Petersen A, Rodrigues S R, Dalmoro V, et al. Anthocyanins as a corrosion inhibitor for 2024-T3 aluminum alloys: a study of electrochemical behavior. Int J Corros Scale Inhib. 2017;6:291.

55. Sánchez J, Fullea J, Andrade C, et al. AFM study of the early corrosion of a high strength steel in a diluted sodium chloride solution. Corros Sci. 2008;50:1820.

56. Qiang Y, Zhang S, Yan S, et al. Three indazole derivatives as corrosion inhibitors of copper in a neutral chloride solution. Corros Sci. 2017;126:295.

57. Arellanes-Lozada P, Olivares-Xometl O, Likhanova NV, et al. Adsorption and performance of ammonium-based ionic liquids as corrosion inhibitors of steel. J Mol Liq. 2018;265:151.

58. Adejoro IA, Ibeji CU, Akintayo DC. Quantum Descriptors and Corrosion Inhibition Potentials of Amodaquine and Nivaquine. Chem Sci J. 2017;8149.

59. Haque J, Verma C, Srivastavaa V, et al. Experimental and quantum chemical studies of functionalized tetrahydropyridines as corrosion inhibitors for mild steel in $1 \mathrm{M}$ hydrochloric acid. Results Physics. 2018;9:1481.

60. Anusuya N, Saranya J, Sounthari P, et al. Corrosion inhibition and adsorption behaviour of some bis-pyrimidine derivatives on mild steel in acidic medium. J Mol Liq. 2017;225:406. 
61. Madkour LH, Elshamy IH. Experimental and computational studies on the inhibition performances of benzimidazole and its derivatives for the corrosion of copper in nitric acid. Int J Ind Chem. 2016;7:195.

62. Ebenso EE, Kabanda MM, Arslan T, et al. Quantum Chemical Investigations on Quinoline Derivatives as Effective Corrosion Inhibitors for Mild Steel in Acidic Medium. Int J Electrochem Sci. 2012;7:5643.

63. Souza ECC A, Rippera BA, Perronea D, et al. Roasted Coffee Extracts as Corrosion Inhibitors for Mild Steel in $\mathrm{HCl}$ Solution. J Mater Res. 2016;19:1276.

64. Guidi GF. Tryptophan as copper corrosion inhibitor in $0.5 \mathrm{M}$ aerated sulfuric acid. Corros Sci. 2002;44:1995.

65. Yurt A, Duran B, Dal H. An experimental and theoretical investigation on adsorption properties of some diphenolic Schiff bases as corrosion inhibitors at acidic solution/mild steel interface. Arab J Chem. 2014;7:732.

66. Schweitzer Philip A. Corrosion of Linings \& Coatings: Cathodic and Inhibitor Protection and Corrosion monitoring. $2^{\text {nd }}$ Edition. Boca Raton: CRC Press; 2006.

67. Ech-chihbi E, Belghiti ME, Salim R, et al. Experimental and computational studies on the inhibition performance of the organic compound "2phenylimidazo [1,2-a]pyrimidine-3- carbaldehyde" against the corrosion of carbon steel in 1.0 M HCl solution. Surf Interface. 2017;9:206.

68. Ituen E, Akaranta O, James A. Evaluation of Performance of Corrosion Inhibitors Using Adsorption Isotherm Models: An Overview. Chem Sci Int J. 2017;18(1):1.

69. Fateh A, Aliofkhazraei M, Rezvanian AR. Review of corrosive environments for copper and its corrosion inhibitors. Arab J Chem. 2020;13:481-544.

70. Saadawy M. Effect of Inorganic Anions on the Pitting Behaviour of Austenitic Stainless Steel 304 in $\mathrm{H}_{2} \mathrm{SO}_{4}$ Solution Containing Chloride Ion. Int $\mathrm{J}$ Electrochem Sci. 2016;11:2345. 